\title{
GERENCIANDO O RELACIONAMENTO ENTRE RECURSOS ESTRATÉGICOS E PRIORIDADES COMPETITIVAS SEGUNDO A VISÃO BASEADA EM RECURSOS
}

\section{MANAGING THE RELATIONSHIP BETWEEN STRATEGIC RESOURCES AND COMPETITIVE PRIORITIES THROUGH THE RESOURCE-BASED VIEW}

\author{
Cláudia Fabiana Gohr* claudiagohr@ct.ufpb.br \\ Yuri Laio Teixeira Veras Silva* yurilaio@gmail.com \\ *Universidade Federal da Paraíba (UFPB), João Pessoa, PB
}

\begin{abstract}
Resumo: As empresas devem desenvolver e melhorar recursos que são considerados estratégicos e que apoiam as suas prioridades competitivas, especialmente aquelas que são importantes para os clientes. Utilizando a visão baseada em recursos como perspectiva teórica, o principal objetivo desse artigo é analisar como os recursos estratégicos podem contribuir para as prioridades competitivas de uma organização que atua no setor logístico. O método de pesquisa adotado foi o estudo de caso com abordagem qualitativa, sendo os principais instrumentos de coleta de dados entrevistas semiestruturada e não estruturada; e, observações sistemáticas. Por meio da pesquisa foi possível constatar que os recursos que mais contribuem para as prioridades competitivas da empresa que precisam de melhorias são: controle de vendas, clientela fiel, experiência dos sócios e feedback ágil aos clientes. Entretanto, desses, apenas a experiência dos sócios proporciona o desenvolvimento de vantagens competitivas sustentáveis. Os demais recursos permitem apenas uma paridade competitiva, entretanto, apoiam prioridades competitivas importantes para a empresa, necessitam, portanto, de maiores investimentos.
\end{abstract}

Palavras-chave: Estratégia de Operações. Prioridades Competitivas. Recursos Estratégicos. Visão Baseada em Recursos. Vantagem Competitiva.

\begin{abstract}
Firms should develop and improve strategic resources that are important for the competitive priorities, especially those that are important to customers. Using resource-based view of the firm as a theoretical perspective, this paper aims to analyze how strategic resources can contribute to the competitive priorities of an organization that operates in the logistic sector. The research method used was the case study using as the main technique of data collection semi-structured and structured interviews; and, systematic observations. The resources that contribute effectively to competitive priorities that need improvement are sales control, loyal customer base, partners experience and agile feedback to customers. However, only the experience of the partners provides to the company sustainable competitive advantage. Others resources identified in the field research provide only a competitive parity, despite this, support important competitive priorities.
\end{abstract}

Keywords: Operations Strategy. Competitive Priorities. Strategic Resources. Resource-Based View. Competitive Advantage.

\section{INTRODUÇÃO}

Em um mercado de alta competitividade, a obtenção da vantagem competitiva é resultante diretamente da diferença dos recursos e capacidades entre as organizações, ou seja, os recursos e as capacidades são fatores primordiais para 
que seja possível implementar as estratégias empresariais em seus diferentes níveis (TEECE, 2009; BARNEY; HESTERLY, 2007; BARNEY, 1991).

As prioridades competitivas envolvem o desenvolvimento e o desdobramento dos recursos da produção que devem estar alinhadas com os objetivos e as estratégias corporativas e competitivas da organização, sendo considerada uma arma competitiva (ANDERSON; CLEVELAND; SCHROEDER, 1989). Portanto, é crucial que uma empresa saiba gerenciar seus recursos de forma eficiente, para reconhecer quais desses apoiam as suas prioridades competitivas, de forma a aproveitar melhor as oportunidades que o mercado proporciona.

Estorilio e Esturilho (2013) desenvolveram um método para orientar a escolha de recursos responsáveis pela prioridade competitiva flexibilidade, considerando a demanda do consumidor e os objetivos da empresa. Os autores utilizaram o QFD (Quality Function Deployment - Desdobramento da Função Qualidade), para desenvolver o método apresentando uma correlação entre quatro níveis da prioridade competitiva flexibilidade (habilidades, dimensões, elementos e recursos provedores) partindo da demanda do consumidor e da estratégia da empresa. Entretanto, diferentemente de Estorilio e Esturilho (2013), este artigo tem como principal objetivo analisar como os recursos estratégicos podem contribuir para as prioridades competitivas de uma organização que atua no setor logístico, utilizando como pano de fundo a visão baseada em recursos (VBR).

Ao verificar a literatura é possível encontrar pesquisas que procuraram analisar o alinhamento entre as prioridades competitivas com outros aspectos do contexto organizacional, como por exemplo, com a estratégia competitiva. Lillis e Sweeney (2013), por exemplo, investigaram as características da estratégia competitiva e da estratégia de operações com a finalidade de avaliar o grau de alinhamento entre elas em organizações de serviços, utilizando como pano de fundo teorias baseada em mercado (PORTER, 1991) e teorias baseadas em recursos (TEECE, 2009). Shavarini et al. (2013) também procuraram desenvolver um modelo operacional cuja finalidade era verificar o relacionamento necessário entre a estratégia competitiva e as prioridades competitivas. Outros trabalhos procuraram analisar o alinhamento entre o ambiente de negócios e as prioridades competitivas das empresas, conforme pode ser verificado na pesquisa de Cai e Yang (2014). 
Dessa forma, este trabalho se diferencia dos demais ao relacionar os recursos considerados estratégicos com as prioridades competitivas de uma empresa, utilizando como perspectiva teórica de análise a VBR. A visão baseada em recursos representa hoje uma das correntes de pensamento mais importantes da área de estratégia empresarial e tem sido foco de pesquisas recentes tanto no âmbito nacional (SANCHES; MACHADO, 2014; STAMATO NETO; ALCANTARA RIBEIRO, 2013; ROSSETTO; VERDINELLI, 2011; POPADIUK; RICCIARDI, 2011) como no internacional (LIN; WU, 2014; PERTUSA-ORTEGA; MOLINA-AZORÍN; CLAVER-CORTÉS, 2010; NATH; NACHIAPPAN; RAMANATHAN, 2010). Essa teoria também vem sendo empregada em pesquisas cujo foco são as prioridades competitivas, conforme pode ser observado nos trabalhos de Santos, Gohr e Varvakis (2012, 2011), Größler (2007) e Coates e McDermot (2002). Gagnon (1999) inclusive salienta a importância da VBR para a estratégia de operações de forma que esta pode ser empregada para integrar melhor os recursos responsáveis pela vantagem competitiva. O autor também acredita que a integração da RBV com a estratégia de operações seja um assunto de grande relevância e deve ser considerado pelos pesquisadores da área.

Para o alcance do objetivo, o artigo está dividido em cinco seções. Após esta introdução, o texto segue com uma breve revisão de literatura. Na seção 3 são descritos os procedimentos metodológicos que nortearam o desenvolvimento do estudo empírico. Na seção 4 são identificados e analisados os recursos e as prioridades competitivas, de forma a verificar como os recursos estratégicos apoiam as prioridades competitivas da organização. Por fim, são apresentadas as considerações finais do trabalho e as recomendações para a continuidade do mesmo.

\section{REVISÃO DA LITERATURA}

A área de operações de uma empresa é de fundamental importância para a implementação da estratégia empresarial, uma vez que esta é uma atividade que gerencia recursos e processos que produz e entrega bens e serviços ao mercado (SLACK; LEWIS, 2009). Portanto, as operações são responsáveis pela execução da 
estratégia empresarial, pois auxilia no desempenho competitivo das organizações (HAYES; WHEELWRIGHT, 1984).

Nesse contexto, a estratégia de operações passou a ser tema de relevância tanto no âmbito empresarial, como no meio acadêmico. Existem na literatura diferentes definições para o termo "estratégia de operações", como pode ser verificado no Quadro 1 ilustrado a seguir. Conforme pode ser observado, não há uma definição universal para o termo, embora os autores concordem em relação a alguns aspectos.

Quadro 1 - Definições para a Estratégia de Operações

\begin{tabular}{|l|c|}
\hline \multicolumn{1}{|c|}{ Definição de Estratégia de Operações } & Autores \\
\hline $\begin{array}{l}\text { É um padrão de decisões que moldam as capacitações de longo prazo de } \\
\text { qualquer operação e sua contribuição para a estratégia global, por meio da } \\
\text { conciliação dos requisitos de mercado com os recursos de operações. }\end{array}$ & Slack e Lewis (2009) \\
\hline $\begin{array}{l}\text { É definida como um conjunto de políticas da manufatura que são designadas para } \\
\text { maximizar o desempenho e apoiar ou liderar a estratégia corporativa. }\end{array}$ & Skinner (2007) \\
\hline $\begin{array}{l}\text { Está relacionada com o alinhamento entre as operações e as prioridades } \\
\text { competitivas atuais e com a seleção e criação das capacitações operacionais que } \\
\text { uma empresa precisará no futuro. }\end{array}$ & Hayes e Pisano (1994) \\
\hline $\begin{array}{l}\text { Envolve o desenvolvimento e a implementação de recursos de produção em total } \\
\text { alinhamento com os objetivos e estratégias da empresa. }\end{array}$ & Swamidass (1986) \\
\hline
\end{tabular}

Fonte: Elaborado pelos autores

Nesse sentido, a estratégia de operações pode ser considerada sob quatro perspectivas, a saber: top down, botton up, requisitos de mercado e recursos de operações (SLACK; LEWIS, 2009). Maiores detalhes sobre cada uma das perspectivas pode ser visualizado no Quadro 2.

Algumas pesquisas já foram desenvolvidas utilizando as diferentes perspectivas da estratégia de operações, como por exemplo Shavarini et al. (2013) que desenvolveram um modelo operacional que estabelecia o relacionamento necessário entre a estratégia de negócios (custo e diferenciação) e a estratégia de operações (custo, qualidade, entrega, flexibilidade e inovação). O modelo incluiu aspectos relacionados ao conteúdo e ao processo da estratégia de operações utilizando as perspectivas top down e a visão baseada em recursos. O modelo desenvolvido pelos autores associou o alinhamento com o desempenho das organizações por meio de um survey com 160 empresas, utilizando, de forma combinada, questionários com perguntas fechadas e entrevistas. 
Quadro 2 - Perspectivas para a estratégia de operações

\begin{tabular}{|l|c|}
\hline \multicolumn{1}{|c|}{ Definição } & \multicolumn{1}{|c|}{ Perspectiva } \\
\hline $\begin{array}{l}\text { A estratégia de operações é o reflexo, de cima para baixo, do que todo o negócio } \\
\text { ou grupo quer fazer. }\end{array}$ & $\begin{array}{c}\text { Perspectiva de cima para } \\
\text { baixo (top-down) }\end{array}$ \\
\hline $\begin{array}{l}\text { A estratégia de operações é uma atividade de baixo para cima onde melhorias em } \\
\text { operações de forma cumulativa montam a estratégia. }\end{array}$ & $\begin{array}{c}\text { Perspectiva de baixo para } \\
\text { cima (bottom-up) }\end{array}$ \\
\hline $\begin{array}{l}\text { A estratégia de operações é a tradução dos requisitos de mercado em decisões } \\
\text { de operações. }\end{array}$ & $\begin{array}{c}\text { Perspectiva dos requisitos } \\
\text { do mercado }\end{array}$ \\
\hline $\begin{array}{l}\text { A estratégia de operações explora as competências dos recursos de operações } \\
\text { em mercados escolhidos. }\end{array}$ & $\begin{array}{c}\text { Perspectiva dos recursos } \\
\text { de operações }\end{array}$ \\
\hline
\end{tabular}

Fonte: Elaborado pelos autores baseado em Slack e Lewis (2009)

Considerando a perspectiva dos requisites de mercado, as prioridades competitivas passam a ser um aspecto de relevância. Existem diferentes designações para o termo prioridades competitivas, como por exemplo, objetivos de desempenho, dimensões estratégicas, prioridades estratégicas ou dimensões de desempenho (SLACK; LEWIS, 2009). Nesse artigo, adotar-se-á o termo prioridades competitivas como se referindo aos aspectos de desempenho das operações que satisfazem os requisitos de mercado e, portanto, que a operação precisa perseguir (SLACK; LEWIS, 2009).

Existem na literatura categorias genéricas de prioridades competitivas apresentadas por diferentes autores, entretanto as categorias mais comumente adotadas são: qualidade, rapidez, confiabilidade, flexibilidade e custo (SLACK; LEWIS, 2009). Essas categorias podem ser desdobradas, levando em consideração as particularidades de cada negócio. Para estabelecer as prioridades que devem ser consideradas pela função operações de uma empresa, é necessário identificar os critérios que são considerados importantes para os clientes e qual é o desempenho da empresa em relação a esses critérios. Nesse sentido, Slack (1994), desenvolveu a matriz importância-desempenho, que pode ser visualizada na Figura 1.

De acordo com o exposto na Figura 1, os critérios competitivos podem ser classificados em: menos importantes, ganhadores de clientes e qualificadores. A matriz importância-desempenho considera as lacunas entre o desempenho atual e o desempenho desejado, de forma a orientar no processo de formulação da estratégia de operações. Convém destacar que a matriz importância-desempenho é bastante difundida na literatura de estratégia de operações e tem sido empregada em diferentes trabalhos. Por exemplo, Santos, Gohr e Varvakis (2012) a empregaram, juntamente com outras ferramentas, para auxiliar no desenvolvimento de um modelo para a análise de critérios de valor percebido em operações de serviços. 
Figura 1 - Matriz Importância-Desempenho

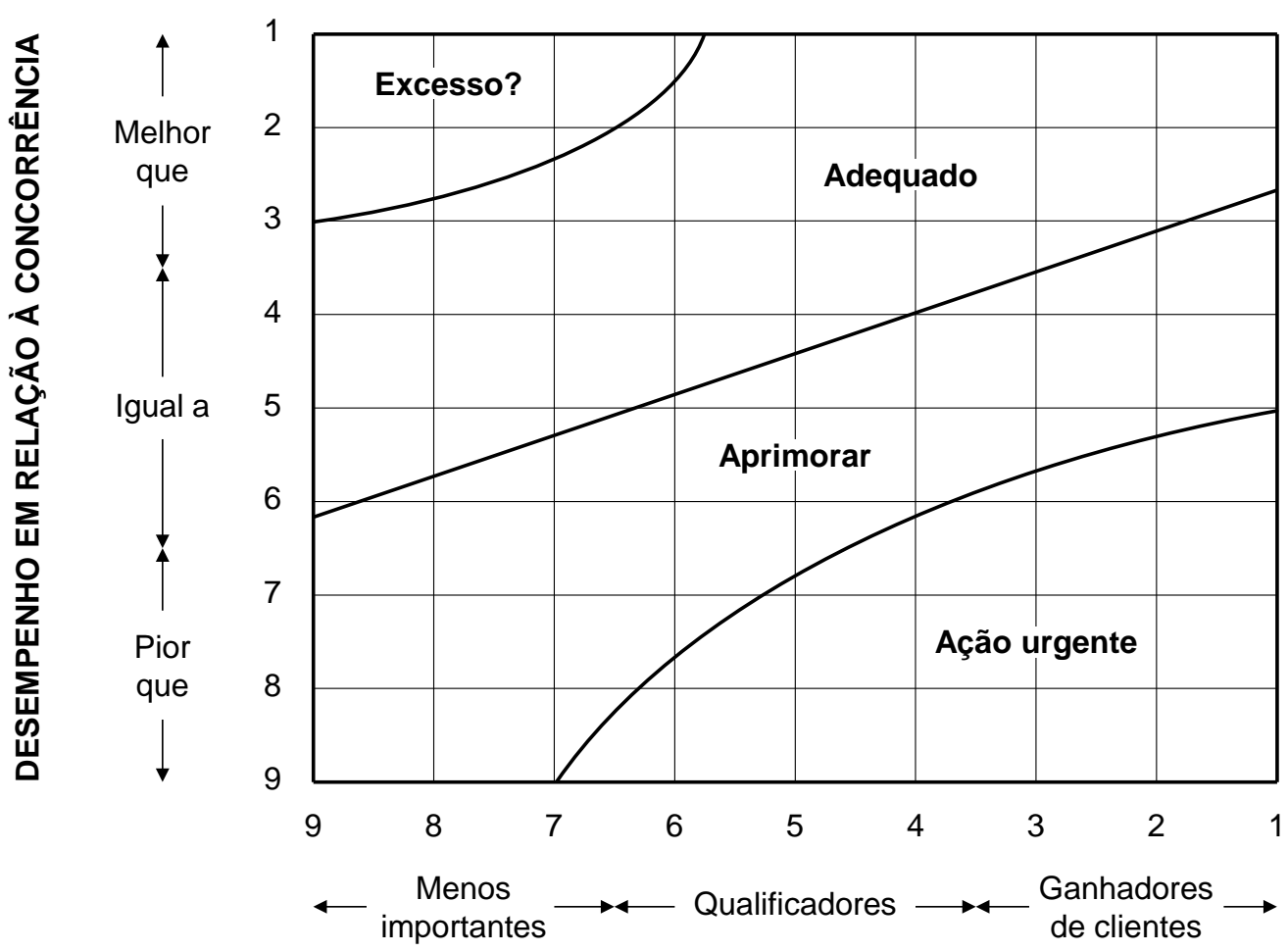

IMPORTÂNCIA PARA OS CLIENTES

Fonte: Slack (1994)

Considerando ainda o Quadro 2, é possível observar que os recursos de operações também são de fundamental importância para a estratégia de operações, pois muitos recursos que permitem o desenvolvimento de vantagens competitivas são formados na base da função operações (COATES; MCDERMOTT, 2002). Uma teoria que tem auxiliado na análise dos recursos de operações que são importantes para as prioridades competitivas é a Visão Baseada nos Recursos da Firma (VBR). De acordo com Barney e Hesterly (2007), para as empresas implementarem as suas estratégias é necessário que reconheçam quais recursos são considerados estratégicos de forma a permitir o desenvolvimento de vantagens competitivas. Assim, a VBR enfatiza os recursos ou capacidades específicas da empresa que irão auxiliar no alcance ou na implementação das prioridades competitivas (COATES; MCDERMOTT, 2002).

Um recurso pode ser definido como um conjunto de ativos controlados pela empresa, que permite que esta implemente as suas estratégias, sendo classificados como financeiros, físicos, individuais e organizacionais (BARNEY; HESTERLY, 
2007). Outra forma de classificar os recursos e adotada por diferentes autores (PENROSE, 1968; WERNERFELT, 1984) é em tangíveis e intangíveis. O primeiro diz respeito aos recursos facilmente observáveis que geralmente incluem recursos físicos e humanos. Já o segundo está relacionado aos recursos que dificilmente conseguem ser identificados e quantificados, como por exemplo, o conhecimento organizacional.

Para ser considerado estratégico e proporcionar o desenvolvimento de vantagens competitivas sustentáveis, é necessário que um recurso atenda aos seguintes requisitos: ser valioso, ser raro, ser difícil de ser copiado e ser organizado pela empresa, o que Barney e Hesterly (2007) denominaram de modelo VRIO (ver Quadro 3), sendo chamado inicialmente de VRIN (valor, raridade e não imitação dos recursos). Convém destacar que no caso do modelo VRIO, a Organização, ou seja, o "O" atua como um fator de ajuste, pois não basta que a empresa tenha recursos valiosos e/ou raros e/ou difíceis de serem copiados. É necessário explorar o potencial desses recursos para auxiliar no processo de implementação de suas estratégias, assim como de suas prioridades competitivas.

O modelo VRIO (ou VRIN) vem sendo comumente empregado em pesquisas cujo foco é a avaliação de recursos e capacidades que contribuem para o desenvolvimento de vantagens competitivas. Por exemplo, Lin e Wu (2014) utilizaram o modelo para analisar quais recursos são mais importantes para serem convertidos em desempenho por meio das capacidades dinâmicas e quais capacidades têm o efeito mais forte nos recursos e seu impacto no desempenho.

Para tanto, realizaram um survey em empresas de Taiwan, chegando a conclusão de que as capacidades podem mediar os recursos das empresas que são VRIN para melhorar o desempenho destas. Stamato Neto e Alcantara (2013) procuraram identificar e avaliar as competências essenciais de frigoríficos brasileiros que exportam carne in natura para Europa. Por meio da análise que fizeram, os autores puderam verificar quais competências eram sustentáveis ou temporárias, utilizando para isso o modelo VRIN. 
Quadro 3 - Modelo VRIO

\begin{tabular}{|c|l|l|}
\hline VRIO & \multicolumn{1}{|c|}{ Questões-chaves } & \multicolumn{1}{c|}{ Características } \\
\hline Valor & $\begin{array}{l}\text { O recurso permite que a } \\
\text { empresa explore uma } \\
\text { oportunidade ambiental e/ou } \\
\text { neutralize uma ameaça? }\end{array}$ & $\begin{array}{l}\text { Para identificar recursos valiosos é analisando a cadeia de valor } \\
\text { pode ser utilizada, pois cada atividade da cadeia necessita da } \\
\text { aplicação e da integração de um conjunto de recursos. }\end{array}$ \\
\hline Raridade & $\begin{array}{l}\text { O recurso é controlado } \\
\text { atualmente apenas por um } \\
\text { pequeno número de } \\
\text { empresas concorrentes? }\end{array}$ & $\begin{array}{l}\text { Um recurso precisa ser controlado por poucos concorrentes } \\
\text { para proporcionar uma vantagem competitiva. }\end{array}$ \\
\hline Imitabilidade & $\begin{array}{l}\text { As empresas sem o recurso } \\
\text { enfrentam uma desvantagem } \\
\text { de custo para obtê-lo ou } \\
\text { desenvolvê-lo? }\end{array}$ & $\begin{array}{l}\text { Além de ser valioso e raro um recurso deve ser difícil de ser } \\
\text { copiado. Isso requer desenvolver mecanismos que tornem a } \\
\text { imitação custosa (condições históricas únicas, ambiguidade } \\
\text { causal, desenvolvimento de patentes e complexidade social). }\end{array}$ \\
\hline Organização & $\begin{array}{l}\text { As outras políticas e os } \\
\text { procedimentos da empresa } \\
\text { estão organizados para dar } \\
\text { suporte à exploração de seus } \\
\text { recursos valiosos, raros e } \\
\text { custosos para imitar? }\end{array}$ & $\begin{array}{l}\text { O "O" atua como um fator de ajuste no modelo, pois não basta } \\
\text { que a empresa tenha recursos valiosos e/ou raros e/ou difíceis } \\
\text { de serem copiados. É necessário explorar o potencial desses } \\
\text { recursos para auxiliar no processo de implementação de suas } \\
\text { estratégias. Isso pode ser feito por meio de uma estrutura formal } \\
\text { de reporte, controles gerenciais formais e informais e políticas } \\
\text { de remuneração. }\end{array}$ \\
\hline
\end{tabular}

Fonte: Elaborado pelos autores, baseado em Barney e Hesterly (2007)

Convém destacar que a competitividade de uma empresa pode ser alcançada por meio da excelência em diversas prioridades competitivas, tais como qualidade, rapidez, confiabilidade, flexibilidade e custo (CAI; YANG, 2014). No entanto, as empresas possuem recursos que são limitados, de modo que muitas vezes deve dedicar seus recursos, especialmente aqueles considerados estratégicos, para a melhoria de prioridades que são consideradas importantes para os clientes.

\section{PROCEDIMENTOS METOLÓGICOS}

A pesquisa relatada neste artigo se propôs a analisar como os recursos estratégicos podem contribuir para as prioridades competitivas de uma organização que atua no setor logístico do Estado da Paraíba. A principal questão de pesquisa, portanto, é "como" e, de acordo com Yin (1994) este tipo de questão é a mais apropriada para pesquisas cujo método empregado é o estudo de caso. Além disso, o estudo de caso é empregado quando existe a necessidade de se desenvolver uma pesquisa exploratória, onde as variáveis ainda não são conhecidas e o fenômeno também não é plenamente compreendido (EISENHARDT, 1989; VOSS; TSIKRIKTSIS; FROHLICH, 2002, YIN, 1994). 
A empresa selecionada atua no setor de logística, mais especificamente no transporte rodoviário de cargas de pequeno e médio porte. Os principais instrumentos de coleta de dados utilizados na pesquisa foram: entrevistas semiestruturada e não estruturadas (com gestores da empresa, funcionários, clientes e três concorrentes) e observações sistemáticas realizadas na empresa e durante as entregas realizadas pela mesma. As entrevistas e observações foram feitas no período de dezembro de 2012 a abril de 2013. As entrevistas foram transcritas, assim como o conteúdo das observações foram anotados, de forma de se pudesse analisar o conteúdo das informações. O Quadro 4 e a Figura 2 ilustram de forma resumida as atividades desempenhadas ao longo do desenvolvimento da pesquisa.

\section{DESCRIÇÃO E ANÁLISE DOS RESULTADOS}

O estudo de caso foi realizado em uma microempresa que atua no setor logístico, com sede no município de João Pessoa/PB. A empresa realiza atividades de distribuição de carga, coletando e entregando cargas de pequeno e médio porte nos municípios de João Pessoa, Campina Grande e Patos.

O faturamento é proveniente de serviços prestados de coleta e entrega de produtos. Dentre seus principais clientes estão empresas maiores do ramo logístico nacional que não tem sede no Estado da Paraíba e que apresentam uma demanda de transporte de produtos em algumas das cidades nas quais a empresa estudada realiza entregas. A Figura 3 ilustra esse processo. 
Figura 2 - Etapas da pesquisa

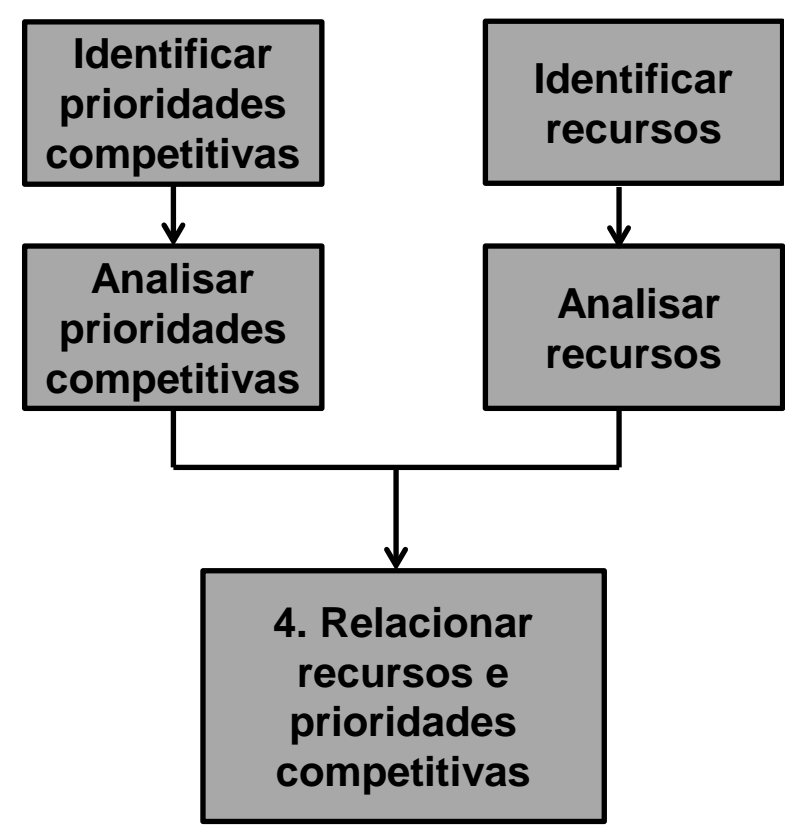

Fonte: Elaborado pelos autores

Quadro 4 - Atividades desempenhadas na pesquisa

\begin{tabular}{|c|c|c|c|}
\hline Etapas da Pesquisa & Finalidade & Como? & $\begin{array}{l}\text { Instrumento de coleta de } \\
\text { dados }\end{array}$ \\
\hline $\begin{array}{l}\text { Identificar } \\
\text { prioridades } \\
\text { competitivas }\end{array}$ & $\begin{array}{c}\text { Compreender as } \\
\text { prioridades competitivas } \\
\text { que norteiam o setor } \\
\text { estudado }\end{array}$ & $\begin{array}{l}\text { Desdobramento das } \\
\text { prioridades: qualidade, } \\
\text { rapidez, confiabilidade, } \\
\text { flexibilidade e custo }\end{array}$ & $\begin{array}{l}\text { - Entrevista semiestruturada } \\
\text { com gestores. } \\
\text { - Entrevistas semiestruturadas } \\
\text { com funcionários. } \\
\text { - Observação assistemática. }\end{array}$ \\
\hline $\begin{array}{l}\text { Analisar prioridades } \\
\text { competitivas }\end{array}$ & $\begin{array}{c}\text { Relacionar as prioridades } \\
\text { identificadas com a } \\
\text { empresa e identificar as } \\
\text { prioridades onde } \\
\text { necessitam } \\
\text { aprimoramentos e ações } \\
\text { urgentes a fim de se melhor } \\
\text { posicionar diante do } \\
\text { mercado } \\
\end{array}$ & $\begin{array}{l}\text { Matriz importância } \\
\text { versus desempenho }\end{array}$ & $\begin{array}{l}\text { - Entrevista semiestruturada } \\
\text { com gestores. } \\
\text { - Entrevistas não estruturadas } \\
\text { com clientes e com três } \\
\text { concorrentes. } \\
\text { - Observação assistemática. }\end{array}$ \\
\hline Identificar recursos & $\begin{array}{l}\text { Identificar os recursos na } \\
\text { empresa objeto de estudo }\end{array}$ & $\begin{array}{l}\text { Categorização de } \\
\text { recursos tangíveis e } \\
\text { intangíveis }\end{array}$ & $\begin{array}{l}\text { - Entrevista semiestruturada } \\
\text { com gestores. } \\
\text { - Entrevistas semiestruturadas } \\
\text { com funcionários. }\end{array}$ \\
\hline Avaliar recursos & $\begin{array}{c}\text { Avaliar o valor, a raridade a } \\
\text { inimitabilidade e a } \\
\text { organização desses } \\
\text { recursos identificados } \\
\end{array}$ & Modelo VRIO & $\begin{array}{l}\text { - Entrevista semiestruturada } \\
\text { com gestores. }\end{array}$ \\
\hline $\begin{array}{l}\text { Relacionar recursos } \\
\text { e prioridades } \\
\text { competitivas }\end{array}$ & $\begin{array}{c}\text { Compreender de que forma } \\
\text { os recursos e as } \\
\text { prioridades competitivas } \\
\text { identificadas estão } \\
\text { relacionadas }\end{array}$ & $\begin{array}{l}\text { Matriz recursos versus } \\
\text { prioridades } \\
\text { competitivas }\end{array}$ & $\begin{array}{l}\text { - Entrevista semiestruturada } \\
\text { com gestores }\end{array}$ \\
\hline
\end{tabular}

Fonte: Elaborado pelos autores 
Figura 3 - Fluxograma dos processos da empresa

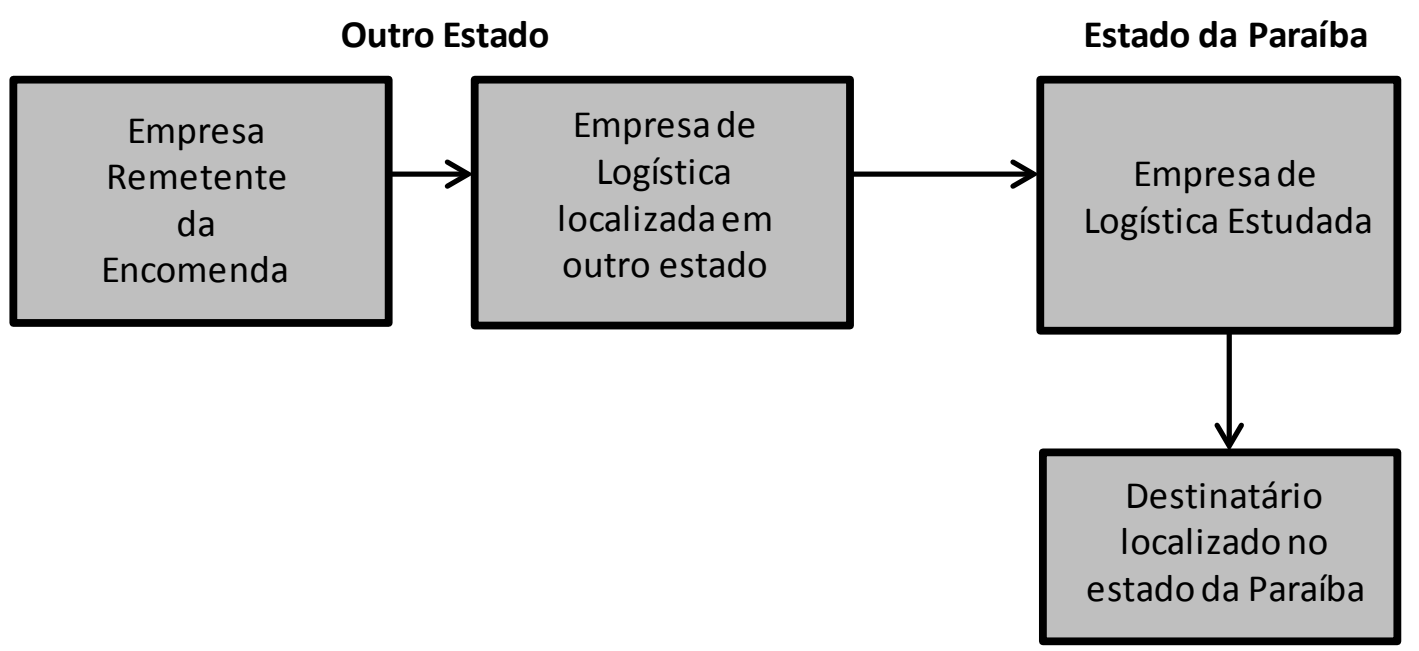

Fonte: Elaborado pelos autores

O processo de prestação do serviço inicia com o contato da empresa cliente com a estudada, realizando a contratação dos serviços. Após a contratação do serviço o cliente envia os produtos por transporte aéreo ou rodoviário. Quando chegam, um funcionário da empresa vai ao local, coleta os materiais enviados e leva-os até o galpão sede da empresa. A partir dali, de acordo com a data de entrega estipulada pelos clientes, a empresa separa as cargas todos os dias pela manhã, e começa a realizar as entregas referentes ao dia, de acordo com cada endereço destinatário enviado pelos clientes para as entregas.

\subsection{Identificação e avaliação dos recursos segundo o modelo VRIO}

Com base nas observações sistemáticas realizadas nos diversos setores da empresa, juntamente com as entrevistas com seus funcionários e gestores, foi possível identificar os recursos da empresa, conforme pode ser visualizado no Quadro 5. A maioria dos recursos é de natureza intangível, decorrente principalmente da grande experiência de seus gestores e funcionários no setor, e do relacionamento de longo prazo com a maioria dos clientes atuais. Os recursos intangíveis geralmente são desenvolvidos ao longo do tempo, podendo envolver complexidade social e ambiguidade causal (BARNEY; HESTERLY, 2007), portanto, são facilmente comprados ou substituídos. 
Quadro 5 - Identificação dos recursos

\begin{tabular}{|c|c|c|}
\hline \multicolumn{3}{|r|}{ RECURSOS } \\
\hline Tangíveis & Instalações & $\begin{array}{l}\text { 1. Local privilegiado; } \\
\text { 2. Depósito com boas capacidades. }\end{array}$ \\
\hline \multirow{3}{*}{ Intangíveis } & Informações & $\begin{array}{l}\text { 3. Relatórios mensais para obter um controle sobre as vendas dos } \\
\text { serviços; } \\
\text { 4. Armazenamento no computador das notas fiscais de cada } \\
\text { entrega realizada para um melhor controle e puder dar um feedback } \\
\text { aos clientes; }\end{array}$ \\
\hline & Experiência & $\begin{array}{l}\text { 5. Ambos os sócios proprietários trabalharam por mais de } 25 \text { anos } \\
\text { na logística da extinta Varig; } \\
6 \text {. Empresa com mais de } 10 \text { anos no mercado e com satisfação dos } \\
\text { clientes por suas entregas rápidas; } \\
\text { 7. Os entregadores têm pleno conhecimento dos mapas da cidade } \\
\text { de João Pessoa, o que auxilia na rápida entrega dos produtos. }\end{array}$ \\
\hline & Relacionamento & $\begin{array}{l}\text { 8. A maioria dos clientes é de longa data, apresentam um perfil de } \\
\text { clientes fiéis, pois sabem da seriedade, agilidade e segurança da } \\
\text { empresa com relação às encomendas. }\end{array}$ \\
\hline
\end{tabular}

Fonte: Elaborado pelos autores

Após a identificação dos recursos, estes foram avaliados segundo os critérios do modelo VRIO, conforme se observa no Quadro 6. Analisando o Quadro 6 podese verificar que os recursos que proporcionam uma vantagem competitiva sustentável para a empresa são: local privilegiado, experiência (dos sócios, da empresa e dos motoristas). Os demais recursos permitem apenas uma paridade competitiva (depósito, controle de vendas empresa e clientes fiéis).

A clientela fixa e fiel tem um alto impacto na lucratividade da organização, pois reduz a variabilidade das encomendas recebidas mensalmente, evitando meses com poucas encomendas e outros com mais, já que boa parte dos clientes solicitam o serviço em quantidades constantes todos os meses, o que gera um faturamento fixo para a empresa, possibilitando maior controle financeiro contra possíveis eventos negativos na demanda variável.

A experiência, juntamente com outros recursos da empresa, permitiu que ela tenha agilidade nas entregas. Os sócios atuam nesse setor a mais de 25 anos, e juntos fundaram a empresa logo após a falência de uma grande empresa de aviação e logística. Ambos sempre trabalharam no município de João Pessoa, o que lhes permite um grande conhecimento do trânsito e locais da cidade, e que auxilia no cotidiano da empresa. 
Quadro 6 - Avaliação dos recursos

\begin{tabular}{|c|c|c|c|c|c|}
\hline Recurso & Valioso? & Raro? & $\begin{array}{l}\text { Custoso de } \\
\text { Imitar? }\end{array}$ & $\begin{array}{l}\text { Explorado } \\
\text { Pela Org.? }\end{array}$ & $\begin{array}{c}\text { Força ou } \\
\text { Fraqueza? É } \\
\text { uma } \\
\text { Vantagem } \\
\text { Competitiva? }\end{array}$ \\
\hline 1 & $\begin{array}{c}\text { Sim. Esse recurso } \\
\text { permite a empresa } \\
\text { uma maior } \\
\text { facilidade para } \\
\text { chegar ao local, que } \\
\text { deve ser visitado } \\
\text { diariamente para } \\
\text { coleta de cargas } \\
\text { que serão } \\
\text { transportadas para } \\
\text { seus destinos. }\end{array}$ & $\begin{array}{l}\text { Sim. É a única } \\
\text { empresa que tem } \\
\text { uma localização } \\
\text { próxima do } \\
\text { aeroporto. }\end{array}$ & $\begin{array}{c}\text { Sim. O local não } \\
\text { tem muitas opções } \\
\text { comerciais, e, } \\
\text { portanto, deve-se } \\
\text { ter um investimento } \\
\text { financeiro } \\
\text { considerável por } \\
\text { parte das empresas } \\
\text { que busquem um } \\
\text { local parecido. }\end{array}$ & Sim & $\begin{array}{c}\text { Força, } \\
\text { competência e } \\
\text { vantagem } \\
\text { competitiva } \\
\text { distintiva } \\
\text { sustentável }\end{array}$ \\
\hline 2 & $\begin{array}{l}\text { Sim, pois propicia } \\
\text { um armazenamento } \\
\text { temporário e seguro } \\
\text { caso haja cargas } \\
\text { que não precisem } \\
\text { ser transportadas } \\
\text { em curto prazo após } \\
\text { serem coletadas. }\end{array}$ & $\begin{array}{l}\text { Não. A maioria das } \\
\text { empresas tem um } \\
\text { depósito grande. }\end{array}$ & $\begin{array}{c}\text { Não. A maioria das } \\
\text { empresas já } \\
\text { apresenta um } \\
\text { depósito bom antes } \\
\text { de iniciar as } \\
\text { atividades neste } \\
\text { setor. }\end{array}$ & Sim & $\begin{array}{c}\text { Força e } \\
\text { Paridade } \\
\text { Competitiva }\end{array}$ \\
\hline 3 e 4 & $\begin{array}{l}\text { Sim. Permitir um } \\
\text { melhor controle das } \\
\text { finanças e das } \\
\text { cargas coletadas e } \\
\text { entregues, assim } \\
\text { como propiciar um } \\
\text { melhor feedback } \\
\text { aos clientes. }\end{array}$ & $\begin{array}{c}\text { Não. Boa parte } \\
\text { das empresas faz } \\
\text { isso. }\end{array}$ & Não & Sim & $\begin{array}{c}\text { Força e } \\
\text { Paridade } \\
\text { Competitiva }\end{array}$ \\
\hline 5,6 e 7 & $\begin{array}{c}\text { Sim. Os } \\
\text { proprietários têm } \\
\text { experiência no setor } \\
\text { e um amplo } \\
\text { conhecimento da } \\
\text { cidade. Isso ajuda } \\
\text { muito tanto no } \\
\text { planejamento das } \\
\text { entregas e coletas, } \\
\text { como no } \\
\text { relacionamento com } \\
\text { os clientes. } \\
\end{array}$ & $\begin{array}{l}\text { Sim. Segundo os } \\
\text { sócios, são poucas } \\
\text { as empresas do } \\
\text { setor no estado } \\
\text { que tem como } \\
\text { proprietário(s) } \\
\text { funcionário(s) com } \\
\text { tanta experiência } \\
\text { nesse ramo. }\end{array}$ & Sim & Sim & $\begin{array}{c}\text { Força, } \\
\text { competência e } \\
\text { Vantagem } \\
\text { Competitiva } \\
\text { distintiva } \\
\text { sustentável. }\end{array}$ \\
\hline 8 & $\begin{array}{l}\text { Sim. Ter clientes de } \\
\text { longa data e fiéis } \\
\text { permitiu o } \\
\text { desenvolvimento de } \\
\text { um relacionamento } \\
\text { de confiança, } \\
\text { permitindo que a } \\
\text { empresa tenha uma } \\
\text { segurança de sua } \\
\text { receita mensal com } \\
\text { clientes fixos. }\end{array}$ & $\begin{array}{l}\text { Não. Várias } \\
\text { empresas do ramo } \\
\text { apresentam esse } \\
\text { recurso. }\end{array}$ & Não & Sim & $\begin{array}{c}\text { Força e } \\
\text { Paridade } \\
\text { Competitiva. }\end{array}$ \\
\hline
\end{tabular}

Fonte: Elaborado pelos autores.

O recurso depósito com grande capacidade se encontra em um local estratégico, bem próximo ao aeroporto, onde se coleta grande parte das cargas que a empresa tem a responsabilidade de buscar e entregar em seu respectivo destino. 
Isso Ihe proporciona uma vantagem competitiva em relação às demais, uma vez que poucas apresentam localização tão estratégica como ela.

Após a identificação e a avaliação dos recursos, as prioridades competitivas foram identificadas e avaliadas, utilizando para isso a Matriz ImportânciaDesempenho, conforme se verifica na subseção a seguir.

\subsection{Identificação e análise das prioridades competitivas}

Por meio das entrevistas e observações realizadas na organização objeto de estudo, foi possível identificar as seguintes prioridades competitivas: preço, confiabilidade nos prazos de entrega, agilidade no atendimento, flexibilidade nas entregas, agilidade na entrega, segurança dos produtos e forma de pagamento.

Após a identificação das prioridades competitivas, foram realizadas entrevistas com clientes (para verificar o grau de importância de cada uma das prioridades) e com os gestores da empresa e concorrentes (para verificar o desempenho da empresa objeto de estudo em relação a esses critérios). Para tanto, foi adotada a seguinte escala de pontuação que pode ser visualizada na Figura 4. Os resultados dessa análise podem ser visualizados no Quadro 7.

Por meio das notas atribuídas no Quadro 7, foi possível elaborar a matriz Importância-Desempenho (Figura 5). Analisando a matriz (Figura 5) foram identificadas as prioridades competitivas que necessitam de ação urgente, de aprimoramento, aquelas que estão adequadas e as que estão recebendo um excesso de recursos. Além disso, foi possível determinar as prioridades consideradas "Ganhadores de Clientes", "Menos Importantes" e as "Qualificadoras".

Assim, constatou-se que a flexibilidade nas entregas é a prioridade competitiva mais problemática para a empresa, pois de acordo com os resultados, necessita de uma ação urgente. As prioridades preço e agilidade no atendimento devem ser aprimoradas, uma vez que o desempenho da empresa está igual ao da concorrência, além de estarem próximas da zona que necessita de ação urgente. 
Figura 4 - Classificação dos fatores competitivos

\begin{tabular}{|c|c|c|c|}
\hline \multirow{3}{*}{$\begin{array}{l}\text { IMPORTÂNCIA } \\
\text { PARA O CLIENTE }\end{array}$} & $\begin{array}{l}\text { Ganhadores } \\
\text { de clientes }\end{array}$ & $\begin{array}{l}\text { Forte } \\
\text { Médio } \\
\text { Fraco }\end{array}$ & $\begin{array}{l}1 \text { Proporciona uma vantagem crucial } \\
2 \text { Proporciona uma vantagem importante } \\
3 \text { Proporciona uma vantagem útil }\end{array}$ \\
\hline & Qualificadores & $\begin{array}{l}\text { Forte } \\
\text { Médio } \\
\text { Fraco }\end{array}$ & $\begin{array}{l}4 \text { Precisa estar dentro do bom padrão do setor } \\
5 \text { Precisa estar dentro do padrão médio do setor } \\
6 \text { Precisa estar a pouca distância atrás do resto do setor }\end{array}$ \\
\hline & Menos importantes & $\begin{array}{l}\text { Forte } \\
\text { Médio } \\
\text { Fraco }\end{array}$ & $\begin{array}{l}7 \text { Não usualmente de importância, mas pode tornar-se importante } \\
8 \text { Muito raramente considerado pelos clientes } \\
9 \text { Nunca considerado pelos clientes }\end{array}$ \\
\hline \multirow{3}{*}{$\begin{array}{l}\text { DESEMPENHO } \\
\text { EM RELAÇÃO À } \\
\text { CONCORRÊNCIA }\end{array}$} & $\begin{array}{l}\text { Melhor que os } \\
\text { concorrentes }\end{array}$ & $\begin{array}{l}\text { Forte } \\
\text { Médio } \\
\text { Fraco }\end{array}$ & $\begin{array}{l}1 \text { Consideravelmente melhor do que os concorrentes } \\
2 \text { Claramente melhor do que os concorrentes } \\
3 \text { Marginalmente melhor do que os concorrentes }\end{array}$ \\
\hline & $\begin{array}{l}\text { Igual aos } \\
\text { concorrentes }\end{array}$ & $\begin{array}{l}\text { Forte } \\
\text { Médio } \\
\text { Fraco }\end{array}$ & $\begin{array}{l}4 \text { Algumas vezes marginalmente melhor do que os concorrentes } \\
5 \text { Mais ou menos igual à maioria de seus concorrentes } \\
6 \text { Levemente abaixo da média da maioria }\end{array}$ \\
\hline & $\begin{array}{l}\text { Pior que os } \\
\text { concorrentes }\end{array}$ & $\begin{array}{l}\text { Forte } \\
\text { Médio } \\
\text { Fraco }\end{array}$ & $\begin{array}{l}7 \text { Usualmente marginalmente pior do que os concorrentes } \\
8 \text { Usualmente pior do que os concorrentes } \\
9 \text { Consistentemente pior do que os concorrentes }\end{array}$ \\
\hline
\end{tabular}

Fonte: Slack (1994)

Quadro 7 - Notas atribuídas na avaliação dos fatores competitivos

\begin{tabular}{|c|c|c|}
\hline & Importância para o cliente & $\begin{array}{c}\text { Desempenho em relação à } \\
\text { concorrência }\end{array}$ \\
\hline Preço (A) & 3 & 5 \\
\hline Confiabilidade nos prazos (B) & 4 & 5 \\
\hline Agilidade no atendimento (C) & 2 & 7 \\
\hline Flexibilidade nas entregas (D) & 1 & 2 \\
\hline Agilidade na entrega (E) & 3 & 4 \\
\hline Segurança dos produtos (F) & 5 & 4 \\
\hline Forma de pagamento (G) & 6 & \multicolumn{2}{|c|}{} \\
\hline
\end{tabular}

Fonte: Elaborado pelos autores 
Figura 5 - Matriz importância-desempenho da empresa

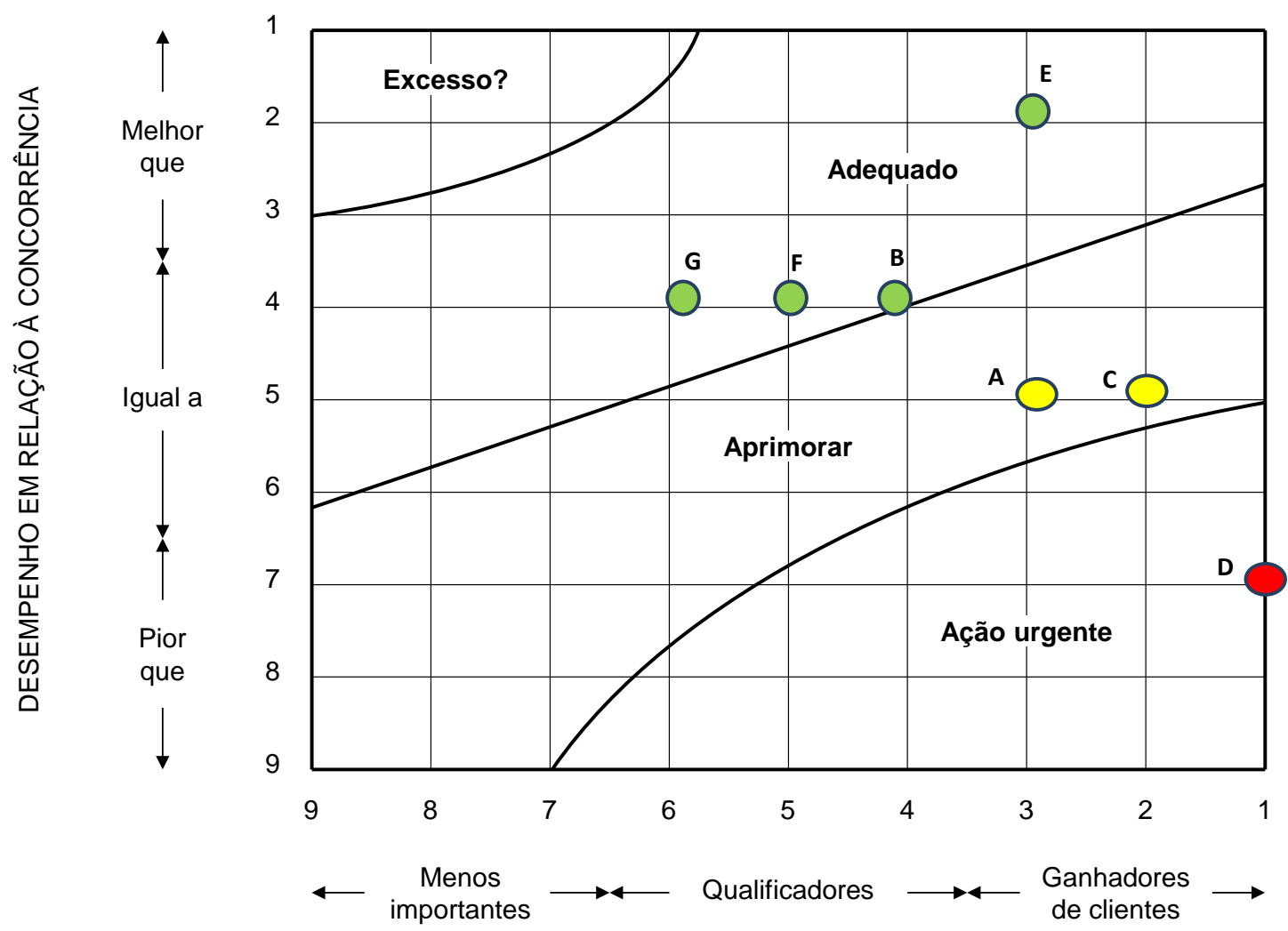

IMPORTÂNCIA PARA OS CLIENTES

Fonte: Elaborado pelos autores

Entretanto, convém destacar que essas três prioridades competitivas são consideradas "Ganhadores de Clientes", portanto, necessitam de uma atenção especial por parte da empresa, no sentido de identificar recursos que apoiem essas prioridades. As demais prioridades competitivas se mostraram adequadas em relação à concorrência. De acordo com a Figura 7, a prioridade mais próxima de atingir a zona de aprimoramento é a confiabilidade nos prazos de entrega.

\subsection{Análise do relacionamento entre os recursos e as prioridades competitivas}

Após a identificação e a avaliação dos recursos e da identificação e análise das prioridades competitivas foi possível verificar o grau de influência que cada recurso tem sobre as prioridades competitivas, de forma a analisar como eles podem apoiar essas prioridades, em especial, aquelas que necessitam de melhorias. Para tanto, foram utilizadas notas que variavam de $(-2)$ a $(+2)$, onde $(-2)$ indicava que o 
recurso possui uma contribuição muito negativa para a prioridade competitiva, (-1) indica que o recurso contribui negativamente, (0) indica neutralidade na relação, $(+1)$ indica que o recurso contribui positivamente e $(+2)$ indica que o recurso contribui muito positivamente para a prioridade competitiva em questão.

Os resultados podem ser observados no Quadro 8 que segue. Convém destacar que os quatro primeiros recursos listados no Quadro 8 são recursos que proporcionam para empresa uma vantagem competitiva sustentável, enquanto que os quatro últimos representam apenas uma paridade competitiva.

Quadro 8 - Relação dos recursos com as prioridades a serem aprimoradas

\begin{tabular}{|c|c|c|c|c|}
\hline \multirow{3}{*}{ RECURSOS } & \multicolumn{3}{|c|}{ GANHADORES DE CLIENTES } & \multirow{3}{*}{$\begin{array}{c}\text { Somatório das } \\
\text { Contribuições por } \\
\text { Recurso }\end{array}$} \\
\hline & \multicolumn{2}{|c|}{ APRIMORAR } & \multirow{2}{*}{$\begin{array}{c}\text { AÇÃO URGENTE } \\
\begin{array}{c}\text { Flexibilidade na } \\
\text { Entrega }\end{array}\end{array}$} & \\
\hline & Preço & $\begin{array}{l}\text { Agilidade no } \\
\text { Atendimento }\end{array}$ & & \\
\hline Local privilegiado & -2 & 1 & 2 & 1 \\
\hline Experiência dos sócios & 1 & 1 & 1 & 3 \\
\hline Experiência da empresa & 1 & 0 & 0 & 1 \\
\hline Experiência dos motoristas & 0 & 0 & 1 & 1 \\
\hline $\begin{array}{l}\text { Depósito de grande } \\
\text { capacidade }\end{array}$ & -1 & 0 & 1 & 0 \\
\hline Controle de vendas & 1 & 2 & 1 & 4 \\
\hline Feedback ágil aos clientes & -1 & 2 & 1 & 2 \\
\hline Clientela fiel & 1 & 1 & 2 & 4 \\
\hline $\begin{array}{c}\text { Somatório das } \\
\text { Contribuições Positivas }\end{array}$ & 4 & 7 & 9 & \\
\hline $\begin{array}{l}\text { Somatório das } \\
\text { Contribuições Negativas }\end{array}$ & -4 & 0 & 0 & \\
\hline Somatório Total & 0 & 7 & 9 & \\
\hline
\end{tabular}

Fonte: Elaborado pelos autores

O Quadro 8 mostra indicadores de grande importância para a tomada de decisão com relação a ações estratégicas da empresa. Das três prioridades que necessitam de melhorias, a flexibilidade na entrega foi a que obteve um maior 
somatório total de contribuições advindas dos recursos, obtendo ainda nenhuma contribuição negativa. Com exceção do recurso experiência da empresa, que apresentou neutralidade na relação, todos os outros indicaram uma contribuição positiva ou muito positiva, como foi o caso dos recursos local privilegiado e clientela fiel.

Entretanto, convém destacar que a clientela fiel, assim como o depósito com grande capacidade, o controle de vendas e o feedback ágil aos clientes são recursos que permitem à empresa apenas uma paridade competitiva, portanto, precisam de aprimoramento, de forma a auxiliar no desenvolvimento de vantagens competitivas sustentáveis. Nesse sentido, esses recursos podem ser os responsáveis pelo mau desempenho da empresa em relação a essas prioridades competitivas. É importante frisar que a flexibilidade na entrega é a prioridade competitiva de maior importância para os clientes, além de a empresa ter obtido um desempenho levemente pior do que o verificado pela concorrência.

Com relação à prioridade agilidade no atendimento, assim como foi mencionado para a flexibilidade na entrega, não há nenhum recurso que contribua de maneira negativa para esta prioridade, entretanto, há três recursos que apresentam uma relação de neutralidade, sendo dois desses recursos responsáveis pelo desenvolvimento de vantagens competitivas. Tal aspecto demonstra, mais uma vez a importância de a empresa investir mais nos recursos feedback ágil ao cliente, controle de vendas e clientela fiel, pois também são recursos importantes para o aprimoramento dessa prioridade competitiva. Conforme afirmam Cai e Yang (2014), as empresas devem implantar e melhorar seus recursos tomando como base as suas prioridades competitivas, especialmente aquelas consideradas muito importantes para os clientes.

A prioridade competitiva preço apresentou o menor somatório total nas contribuições advindas dos recursos, obtendo contribuição negativa de três recursos: local privilegiado, depósito com grande capacidade e feedback ágil aos clientes. Em relação aos dois primeiros recursos (depósito com grande capacidade e local privilegiado) esse resultado pode ser explicado pelo alto custo fixo de se manter uma estrutura do porte da empresa e na localização atual, na qual deve ser ressarcida por meio das receitas. Em relação ao recurso feedback ágil ao cliente, esse resultado é justificado devido ao elevado investimento para adquirir o software 
de gerenciamento de clientes que atualmente é utilizado na empresa, assim como os pagamentos mensais efetuados para o fornecedor e destinados à manutenção do sistema.

O Quadro 9 ilustra o somatório total das contribuições recebidas por cada uma das prioridades competitivas que precisam de aprimoramento, nas quais foram listadas anteriormente. É importante ressaltar que as três prioridades competitivas listadas são considerados critérios ganhadores de clientes, portanto, são fundamentais para a obtenção de vantagens competitivas.

Quadro 9 - Contribuições recebidas dos recursos para as prioridades competitivas e somatório das contribuições por recurso

\begin{tabular}{|c|c|}
\hline PRIORIDADES COMPETITIVAS & $\begin{array}{c}\text { SOMATÓRIO DAS CONTRIBUIÇÕES } \\
\text { DOS RECURSOS PARA CADA } \\
\text { PRIORIDADE }\end{array}$ \\
\hline Flexibilidade na Entrega & 9 \\
\hline Agilidade no Atendimento & 7 \\
\hline Preço & 0 \\
\hline RECURSOS & SOMATÓRIO DAS CONTRIBUIÇÕES \\
\hline Controle de vendas & 4 \\
\hline Clientela fiel & 4 \\
\hline Experiência dos sócios & 3 \\
\hline Feedback ágil aos clientes & 2 \\
\hline
\end{tabular}

Fonte: Elaborado pelos autores

Dessa forma, analisando o somatório das contribuições que os recursos proporcionam para cada prioridade competitiva, foi possível identificar quais recursos são mais apoiadores e, portanto, apresentam um maior índice de contribuição para as prioridades competitivas. No mesmo Quadro 9 também é possível perceber que os recursos que mais contribuem para a maximização do desempenho das prioridades competitivas são: controle de vendas, clientela fiel, experiência dos sócios e feedback ágil aos clientes. Entretanto, desses, apenas a experiência dos sócios proporciona o desenvolvimento de vantagens competitivas sustentáveis segundo os critérios do modelo VRIO. Os demais permitem apenas uma paridade competitiva, portanto precisam de maiores investimentos. Esse 
resultado pode explicar o mau desempenho da empresa em relação aos critérios competitivos flexibilidade na entrega e agilidade no atendimento.

Devido à empresa possuir uma localização próxima ao aeroporto (principal ponto de coleta de cargas), sua localização é estratégica e próxima dos principais clientes, fornecedores e diversas outras empresas que são clientes em potencial e que podem vir a necessitar dos serviços oferecidos pela organização estudada. Porém, o custo de se manter uma estrutura com uma localização privilegiada é alto, impactando no preço final do serviço prestado de forma muita negativa. Tais fatores são importantes argumentos para explicar o motivo pelo qual o recurso estratégico "local privilegiado" ter contribuído de forma positiva para a agilidade no atendimento e flexibilidade nas entregas, porém, de maneira muito negativa para o preço.

Maiores investimentos em estratégias de fidelização dos clientes permitirá que a empresa tenha maior conhecimento de seus clientes, podendo traçar um plano estratégico de entregas personalizado com cada um e, assim, favorecer a flexibilidade nas entregas. Com a fidelização dos clientes pode-se ainda proporcionar à proximidade entre as organizações, tornando o atendimento mais ágil, personalizado e eficaz.

Os resultados da análise comprovam que uma boa organização da carteira de clientes assim como atender às solicitações de serviços são cruciais para o sucesso da empresa no mercado, pois, em um mercado de ampla competição e de serviço tão homogêneo como é o setor logístico, o gerenciamento de cliente e de serviços pode aprimorar significativamente as prioridades competitivas da organização, proporcionando, dessa forma, o desenvolvimento de vantagens competitivas sustentáveis ao longo do tempo.

\section{CONSIDERAÇÕES FINAIS}

O cenário competitivo vem se tornando cada vez mais acirrado, especialmente para as pequenas empresas, e, para sobreviverem no mercado e expandirem seus horizontes, é necessário utilizar da melhor forma possível seus recursos e capacidades, alinhadas com as prioridades competitivas, de maneira que as empresas possam usufruir das oportunidades do mercado. Dessa forma, do ponto de vista empresarial, a pesquisa trouxe luz assuntos que não eram discutidos 
na empresa pesquisada, mas que, a partir dos resultados revelados, pode direcionar o foco de seu gerenciamento estratégico.

Assim, em relação à contribuição prática dessa pesquisa, a empresa pôde identificar recursos que são importantes, pois proporcionam o desenvolvimento de vantagens competitivas sustentáveis, segundo o modelo VRIO, portanto são considerados estratégicos para a organização. Por meio desse modelo, os gestores também identificaram recursos que precisam de aprimoramento, pois estão permitindo para a empresa apenas uma paridade competitiva.

Outra contribuição para a empresa diz respeito à identificação das prioridades competitivas, e por meio da matriz importância-desempenho, constatou-se quais eram as prioridades que são "Ganhadores de Clientes" e que precisam ser melhoradas, pois a organização está com um desempenho abaixo da concorrência.

Por meio da identificação dos recursos e das prioridades competitivas que precisam ser melhoradas na empresa foi possível desenvolver a matriz de relacionamento "Recursos versus Prioridades Competitivas", sendo esta uma contribuição importante desse artigo, tanto para a empresa como para o meio acadêmico. Por meio da matriz foi possível identificar a contribuição de cada recurso em relação àquelas prioridades que precisam de melhorias. Dessa forma, a matriz sinalizou para aos gestores o motivo pelo mau desempenho da empresa em relação aos critérios competitivos considerados "Ganhadores de Clientes", pois grande parte dos recursos que têm uma forte relação com essas prioridades (principalmente flexibilidade na entrega e agilidade no atendimento) são recursos que proporcionam apenas uma paridade competitiva para a organização objeto de estudo.

Convém ressaltar que as pesquisas cujo foco era a análise do alinhamento entre as prioridades competitivas e outros aspectos do contexto organizacional, poucas focaram nos recursos estratégicos, sendo esta outra contribuição desse trabalho. Além disso, grande parte dos trabalhos utilizaram o survey como método de pesquisa. Nesse sentido, ao adotar o estudo de caso para a análise em profundidade de uma determinada realidade, este trabalho trouxe a luz aspectos que não seriam identificados, caso tivesse adotado um método quantitativo, tal como o survey.

Para dar continuidade à pesquisa, sugere-se que sejam desenvolvidos trabalhos por meio da adoção de modelos matemáticos que procurem verificar o 
nível de investimento necessário para o aprimoramento dos recursos de forma que a empresa alcance um desempenho acima da concorrência em relação aos critérios competitivos listados anteriormente. Outra sugestão para a continuidade desse trabalho diz respeito à análise de como os recursos considerados estratégicos podem contribuir para o desenvolvimento das capacidades da organização. Também é recomendável que sejam feitas análises comparativas dos recursos estratégicos de diferentes empresas que atuam no mesmo setor, por meio de surveys, de modo a verificar a possibilidade de generalização de alguns dos resultados dessa pesquisa.

Para finalizar, a aplicação das etapas desenvolvidas nesta pesquisa em uma amostra maior de empresas para verificar o grau de aplicabilidade principalmente da matriz "recursos versus prioridades competitivas" por meio dos critérios factibilidade, usabilidade e utilidade propostos por Platts (1993), seria outra sugestão de pesquisa.

\section{REFERÊNCIAS}

ANDERSON, J. C.; CLEVELAND, G.; SCHROEDER, R. G. Operations strategy: a literature review. Journal of Operations Management, v. 8, n. 2, p. 133-158, 1989.

http://dx.doi.org/10.1016/0272-6963(89)90016-8

BARNEY, J. B., HESTERLY, W. S. Administração estratégica e vantagem competitiva. São Paulo: Pearson Prentice Hall, 2007.

BARNEY, J. Firm resource and sustained competitive advantage. Journal of Management, v. 17, n. 1, p. 99-120, 1991. http://dx.doi.org/10.1177/014920639101700108

CAI, S.; YANG, Z. On the relationship between business environment and competitive priorities: the role of performance frontiers. International Journal of Production

Economics, v. 151, n. 1, p. 131-145, 2014. http://dx.doi.org/10.1016/j.ijpe.2014.02.005

COATES, T. T.; MCDERMOTT, C. M. An exploratory analysis of new competencies: a resource based view perspective. Journal of Operations Management, v. 20, n. 5, p. 435450, 2002. http://dx.doi.org/10.1016/S0272-6963(02)00023-2

EISENHARDT, K. M. Building theories from case study research. Academy of Management Review, v. 14, n. 4, p. 532-550, 1989. http://dx.doi.org/10.5465/AMR.1989.4308385

GAGNON, S. Resource-based competition and the new operations strategy. International Journal of Operations \& Production Management, v. 19, n. 2, p. 125-138, 1999. http://dx.doi.org/10.1108/01443579910247392

GRÖßLER, A. A dynamic view on strategic resources and capabilities applied to an example from the manufacturing strategy literature. Journal of Manufacturing Technology

Management, v. 18, n. 3, p. 250-266, 2007. http://dx.doi.org/10.1108/17410380710730594 
HAYES, R H.; PISANO, G P. Beyond world-class: the new manufacturing strategy. Harvard Business Review, v. 72, n. 1, p. 77-86, 1994.

HAYES, R. H.; WHEELWRIGHT, S. C. Restoring our competitive edge: competing through manufacturing. New York: John Wiley \& Sons, 1984.

LILLIS, B.; SWEENEY, M. Managing the fit between the views of competitive strategy and the strategic role of service operations. European Management Journal, v. 31, n. 6 p. 564590, 2013. http://dx.doi.org/10.1016/j.emj.2012.10.001

LIN, Y.; WU, L. Exploring the role of dynamic capabilities in firm performance under the resource-based view framework. Journal of Business Research, v. 67, n. 3, p. 407-413, 2014. http://dx.doi.org/10.1016/.j.jbusres.2012.12.019

NATH, N.; NACHIAPPAN, S.; RAMANATHAN, R. The impact of marketing capability, operations capability and diversification strategy on performance: a resource-based view. Industrial Marketing Management, v. 39, n. 2, p. 317-329, 2010.

http://dx.doi.org/10.1016/j.indmarman.2008.09.001

PENROSE, E.T. The theory of the growth of the firm. Oxford: Basil Blackwell, 1968. PERTUSA-ORTEGA, E. V.; MOLINA-AZORÍN, J. F.; CLAVER-CORTÉS, E. Competitive strategy, structure and firm performance: a comparison of the resource-based view and the contingency approach. Management Decision, v. 48, n. 8, p. 1282- 1303, 2010. http://dx.doi.org/10.1108/00251741011076799

PLATTS, K. W. A process approach to researching manufacturing strategy. International Journal of Operations \& Production Management, v. 13, n. 8, p. 8-17, 1993. http://dx.doi.org/10.1108/01443579310039533

POPADIUK, S.; RICCIARDI, G. Conversão do conhecimento é fonte de vantagem competitiva sustentável? uma análise empírica sob a perspectiva da Resource-based view. Gestão \& Produção, v. 18, n. 1, p. 193-204, 2011. http://dx.doi.org/10.1590/S0104530X2011000100014

PORTER, M. E. Estratégia competitiva: técnicas para análise de indústrias e da concorrência. 7.ed. Rio de Janeiro: Campus, 1991.

RIBEIRO, R.; ROSSETTO, C. R.; VERDINELLI, M. A. Comportamento estratégico da empresa e a visão baseada em recursos: um estudo no setor varejista de material de construção. Gestão \& Produção, v. 18, n. 1, p. 175-192, 2011.

http://dx.doi.org/10.1590/S0104-530X2011000100013

SANCHES, P. L. B.; MACHADO, A. G. C. Estratégias de inovação sob a perspectiva da Resourced-based view: análise e evidências em empresas de base tecnológica. Gestão \& Produção, v. 21, n. 1, p. 125-141, 2014. http://dx.doi.org/10.1590/S0104530X2014005000005

SANTOS, L. C.; GOHR, C. F.; VARVAKIS, G. Um método para identificação e análise de competências e recursos estratégicos das operações de serviços. Gestão \& Produção, v. 18, p. 791-808, 2011. http://dx.doi.org/10.1590/S0104-530X2011000400008

SANTOS, L. C.; GOHR, C. F.; VARVAKIS, G. Prioridades competitivas para a estratégia de operações de serviços: uma análise dos critérios de valor percebido de uma academia de 
ginástica. Revista Produção Online, v. 12, p. 133-158, 2012.

http://dx.doi.org/10.14488/1676-1901.v12i1.837

SHAVARINI, S. K. et al. Operations strategy and business strategy alignment model (case of Iranian industries). International Journal of Operations \& Production Management, v. 33, n. 9, p. 1108-1130, 2013. http://dx.doi.org/10.1108/IJOPM-12-2011-0467

SKINNER, W. Manufacturing strategy: the story of its evolution. Journal of Operations Management, v. 25, n. 2, p. 328-335, 2007. http://dx.doi.org/10.1016/j.jom.2006.10.008

SLACK, N. The importance-performance matrix as a determinant of improvement priority. International Journal of Operations \& Production Management, v. 14, n. 5, p. 59-75, 1994. http://dx.doi.org/10.1108/01443579410056803

SLACK, N.; LEWIS, M. Estratégia de operações. 2.ed. Porto Alegre: Bookman, 2009.

STAMATO NETO, J.; ALCANTARA, R. L. C. Competências essenciais presentes em frigoríficos brasileiros exportadores para a Europa: um estudo multicaso. Revista Produção Online, v.13, n. 1, p. 180-207, 2013. http://dx.doi.org/10.14488/1676-1901.v13i1.1107

SWAMIDASS, P. M. Manufacturing strategy: its assessment and practice. Journal of Operations Management, v. 6, n. 4, p. 471-484, 1986.

http://dx.doi.org/10.1016/02726963(86)90018-5

TEECE, D. J. Dynamic capabilities and strategic management. New York: Oxford University Press, 2009.

VOSS, C.; TSIKRIKTSIS, N; FROHLICH, M. Case research in operations management. International Journal of Operations Management. v. 22, n. 2, p. 195-219, 2002. http://dx.doi.org/10.1108/01443570210414329

WERNERFELT, B. A resource-based view of the firm. Strategic Management Journal, v. 5, n. 2, p.171-180, 1984. http://dx.doi.org/10.1002/smj.4250050207

YIN, R. K. Case study research: design and methods. 2. ed. Sage: Thousand Oaks, 1994.

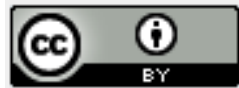

Artigo recebido em 06/12/2014 e aceito para publicação em 07/02/2015 DOI: http://dx.doi.org/ 10.14488/1676-1901.v15i2.1939 